\title{
Parents' Participation in Public Primary Schools in Botswana: Perceptions and Experiences of Headteachers
}

\author{
Nkobi Owen Pansiri ${ }^{1} \&$ Philip Bulawa ${ }^{1}$ \\ ${ }^{1}$ University of Botswana, Botswana \\ Correspondence: Nkobi Owen Pansiri, University of Botswana, Botswana. E-mail: pansirio@mopipi.ub.bw
}

Received: March 10, 2013

Accepted: March 19, 2013 Online Published: April 26, 2013

doi:10.5539/ies.v6n5p68

URL: http://dx.doi.org/10.5539/ies.v6n5p68

\begin{abstract}
The idea of involving parents in the school system is universal and as old as the history and philosophy of education itself. This study investigated the public school headteachers' experiences and perceptions about the level of parental involvement in the public primary school system in Botswana. The theories guiding this study are that of Epstein's three spheres of influence and Hoover-Dempsey and Sandler's model of three level construct. A quantitative design through a medium of a questionnaire for data collection was employed. Out of a total 745 headteachers of public or government primary schools, $63.4 \%$ responded to the questionnaire. An important result of the study is that there is minimal parental support especially in rural and remote areas and in boarding primary school system in Botswana. Three recommendations of this study are, the creation of a parent education programme, a policy for the support and participation of parents of children in boarding schools, and further research to tap on the voices of the parents.
\end{abstract}

Keywords: school, family and community, parental participation, parents and teachers association, remote area dwellers, boarding primary school, parent education programme

\section{Background}

Botswana is a Southern African, land locked, semi-arid and middle-income country of 582000 square kilometres, with a total sparsely spread population of 2038228 million people as at 2011 Population and Housing Census, growing at an annual rate of $1.9 \%$ (Republic of Botswana, 2011). It has one of the lowest population densities in the world (3.2 inhabitants per square kilometer) and it is estimated to be the size of Kenya or France (Nyati-Ramahobo, 2004). Roughly, half of the population lives in urban areas and the other half in rural areas (Pridmore, 1995). It gained its independence in 1966 after 81 years of British protectorate. According to the education statistics of 2011, Botswana has 805 primary schools. Out of this number, 745 are public or government primary schools and 60 are private schools or what is referred to as English Medium schools. These are mostly found in urban and some semi-urban centres. Out of the 745 public schools, 27 schools in remote areas were running boarding system that admitted children who lived in settlements far away from the main economic centres and were hard to reach in terms of geographical terrain, due to poor communication and poorly developed infrastructures.

The idea of involving parents in the school system is universal and perhaps as old as the history and philosophy of the education system. The traditional education systems of Botswana were culturally based, driven by community leaderships and focusing on reproducing useful members of the societies. When pre-independence missionaries arrived in the Bechuanaland (Note 1) they worked with traditional leaders (chiefs and community elders) to mobilize parents for participation in their education agendas. They did so, because they found structures where societies and communities had education systems that were parent-driven. This approach was adopted and used during the colonial era. The colonial government worked closely with chiefs and missionaries to engage parents in building school infrastructure through self reliance strategies.

As soon as Botswana gained independence in 1965, local authorities (Note 2) were established and mandated to run primary education (which was then basic education) while the Ministry of Education (MoE) took responsibility for secondary and tertiary education. This was the first initiative to extend formal educational opportunity to every community in the country. Pansiri and Pansiri (2011) reveal that at that stage the country immediately adopted democracy, development, unity and self-reliance as the four national principles to guide the country's philosophy of nation building, or what is known as Education for Democracy. Pansiri and Pansiri 
further state that "within the philosophy of self-reliance, [Parents and Teachers Associations (PTA)] became a cornerstone in the impetus for educational development" (p. 284).

The history of education, therefore, shows that school and family relationship is a major component of a successful and effective school. This argument has been found to be stronger in the middle class parents especially in the Western-Euro (Note 3) countries (Berger, 1991). In these countries, as anywhere else in the world, parental involvement (PI) and/or parental engagement (PE) are much more pronounced at infant and primary education levels and diminish as children progress to higher levels of education (Desforges \& Abouchaar, 2003; Harris \& Goodall, 2006). Desforges and Abouchaar (2003, p. 4) argue that PI refers to contacts that parents have "with schools to share information; participation in school events; participation in the work of the school; and participation in school governance". PE means "the support that parents can show for their children, the encouragement given and the role models provided" (Harris \& Goodall, 2006, p. 59). PI plays a significant role in enhancing the development of school as a learning organization while PE remains a critical factor in the success of a learner in the classroom. However, both PI and PE are issues of school and family connections that enhance the learning and growth of a child. The legitimacy of parents and school relationship is the more reason to improve both PI and PE for school improvement and increased learner achievement. This study, therefore, uses 'parental participation' to connote interchangeability and functionality of PI and PE.

\subsection{Policy on School-Community Relationship}

The First Commission on Education of 1977 in its philosophical framework of self-reliance argues that "communities and parents must accept their responsibility for the education and training of the young" (Republic of Botswana, 1977, p. 29). This commitment to formal education and self-reliant was further strengthened when the commission stressed that it was the responsibility of the entire generation of adults to participate in the upbringing of children. The commission emphasized the need for government to provide moral and material support to communities that started schools, training and courses with self help. On the responsibility of parents as a collective, the commission implored parents to "give time to school matters through parent-teacher associations and to contribute to the physical upkeep and maintenance of the premises..." (p. 56). Parents are therefore, required to make sure children go to school on time, feed adequately, are not overtaxed with home chores over school work, visit school, and hold frequent discussions with teachers to foster learning progress. This was the early educational policy on PI in formal education in Botswana. It was reinforced by the Revised National Policy on Education of 1994 (RNPE), the current Botswana education blueprint, that "the government should intensify the efforts to encourage the establishment of PTAs" (Republic of Botswana, 1994, p.52). This second Botswana education policy legitimized PTAs to "provide an effective forum for schools to keep in close contact with the communities that they serve, and therefore, ensure that parents take an interest in, and contribute to the education of their children". It also posits, "PTAs should be encouraged to add...for example in the provision of computers and library books, in order to enrich the curriculum of the [primary] school" (p.16). PTAs therefore, carry a mandate to participate and contribute in school and educational development. Every school is expected to have a PTA and to ensure that parents participate in school activities. It has been observed, however, that while governments and educational policies require schools to have PTAs that support schools, government or public schools in many African countries find it hard to mobilize parents for the PTA functions (Sifuna, 2007; Pansiri, 2008a; Pansiri \& Pansiri, 2011). In the ultimate and as it is in Botswana, "government plays a major role compared to parents and the community" (Pansiri \& Pansiri, 2011, p. 287) leading to the predominance of bureaucratic type of school governance (Pansiri, 2008a) where parents are at arms length with school programmes.

\subsection{Fees and Parental Contribution in Botswana}

The policy of school fees is inevitably an enforced act for PI in the education of their children. At independence, primary education was accessible through school fees of R6.00 (South African Rand) per year per child. The fees were unaffordable to most Batswana especially the then $45 \%$ of the rural population that lived in poverty, subsisting on meager outputs from crops and livestock, hunting and food gathering (Republic of Botswana, 1977:14). As a result, most rural children could not enroll in primary education. In 1973, school fees were reduced to R3.00 per year per child. This move helped to open access to many children. However, as a result of the low yield in crop production, cattle diseases and the drought of the 1970s, the cost of living became very difficult for rural citizens. In response, and following the 1977 Education Policy and the implementation of the National Development Plan (NDP) 5, that aimed to achieve universal access to primary education, school fees were abolished in 1980. The abolition of school fees resulted in increased school enrolments and the expansion of primary education. For example, the 394 primary schools with 156890 pupils in 1979 increased to 518 primary schools with 209345 pupils by 1984 . The Junior Certificate admissions increased from $38 \%$ of its 
intake in 1984 to $67 \%$ in 1991 (Republic of Botswana, 1993). During the implementation of NDP 8, Botswana reported an achievement of $100 \%$ transition rate from primary to junior secondary (Republic of Botswana, 2003), an excellent record in terms of achieving universal access to ten-years of basic education in Africa.

\subsection{RADS and Parental Involvement}

Between 1980 and 2005 basic education was free but not compulsory. In 2006 a policy of cost-sharing which re-introduced school fees for post-primary education was promulgated. However, this policy has since excluded the poor, especially children who are under the care of the Remote Area Development Programme (Note 4) (RADP). RADP is a 1974 Botswana Government educational disenfranchisement policy specific for the remote area people especially Basarwa (San). It is meant to uplift their social and economic status (Pridmore, 1995). While UN Article No 26 declared that elementary or primary education should be free and compulsory, Botswana adopted a free primary education but not compulsory approach. It's a policy of persuasion, which encourages parents to engage with their moral obligation to send their children to school on their own free will. On the other hand and through its political obligation, the government improved open access by building boarding primary and junior secondary schools to cater for as many remote and rural children as possible. The RADP also provide food, toiletry and clothing packages to improve the school retention for students in RADP settlements. Despite this initiative, many children from these poor families perform poorly in national examinations and some leave schools before they complete their basic education programme (Republic of Botswana, 2004; Pansiri, 2008a; 2008b; 2011).

It is, however, not clear how school fees and its abolition affected PI in Botswana government school system. The case is different in private or English Medium schools where it is 'a must' that parents participate in their children's education. English medium schools are for parents of high socioeconomic background as these parents can afford to pay school fees. School retention and pass rates are comparatively and relatively higher in the English medium schools than in the public ones (Pansiri, 2011).

It is therefore, against this trend that this study is motivated to establish experiences of Botswana public primary school heads with regard to participation of parents in the basic education system.

\section{Aims and Objectives of the Study}

The current status is that government plays a major role compared to parents and the community in the provision of public primary education. Public primary schools have higher records of poor performance and low retention than private schools. The aim of the study was therefore, to investigate the public school headteachers' experiences and perceptions about level of PI in the public primary schools throughout Botswana. Based on a null hypothesis that there is no significance difference between the public primary school heads experiences and challenges they face with PTAs, the research objectives were to:

$>$ assess the headteachers' perceptions of the work of PTA

$>$ establish headteachers experiences on the degree of parental involvement in PTA activities

$>$ reflect how headteachers rate the support that parents give to their children's learning

$>$ identify challenges experienced by headteachers with their PTAs

> solicit headteachers' suggestions on effective PTA and active parental participation in their schools

\section{Theoretical Frameworks}

Two theoretical perspectives were used in this study. These were Epstein's theory of the three spheres of influence and Hoover-Dempsey and Sandler's model of three level construct. Each of these perspectives is discussed briefly below.

Epstein's (1995) theory of the three spheres of influence - 'school, family and community' emphasizes building partnerships, relatedness/connections and the recognition of the overlapping of these spheres. She identifies these three as 'major contexts' in which children learn and grow. Schools can either communicate very effectively to reach out to both the families and the community separately or could establish high-quality communications and interaction systems to bring the spheres closer together (p. 702). Epstein generated two models for this theory namely the external and internal. In the external model, she argues that school, family and community have practices where each could remain separate and influence children's learning and growing separately. On the other hand, the internal interaction model functions when the interaction takes place within each of the spheres. For example, at family levels, there is interaction between individuals which affect the child. The same occurs at school and at community levels. It is, however, fundamental in this theory that a child (who is learning and growing) remains at the center of school, family and community relationship. These spherical relationships could 
be defined in terms of their social, economic and emotional characteristics. For example, issues of poverty, parenting, and culture will always affect the child. As such, this theory helps this study to interrogate and navigate issues of parental participation.

Hoover-Dempsey and Sandler (1997) generated a model to explain the parents' decisions to partake in the education of their children. The model has constructs of three levels. The first level construct is that parent's decision to be involved is influenced by the way he/she sees his/her role in the life of the child. The more a parent appreciates his/her role the more he/she gets involved. Secondly, a parent's involvement is influenced by his/her sense of efficacy for helping the child to succeed in school. This suggests that parents are influenced by believing in their own ability and confidence that they can help their children to learn and succeed. The third construct is that participation of a parent is a result of "general invitations, demands, and opportunities for parental involvement presented by both the child and the child's school" (p. 9). This means that parental participation is a parents' response to invitation and/or demand by either the child or the school. These three constructs give useful theoretical lenses through which parental participation in Botswana could also be assessed.

Any attempt to understand issues of parental participation cannot ignore the Epstein's three spheres of influence (school, family and community) and the Hoover-Dempsey and Sandler's three-levels construct. This study, therefore, positions itself within these two theoretical positions. These stand relevant and valid for the understanding of the status of parental involvement in public primary education trends and practices in Botswana and elsewhere.

\section{Literature Review}

Across the globe, PTAs are legitimate but voluntary structures that are meant to mediate between schools and communities; between teachers and parents; and between schools and families. While these institutions are voluntary they have become 'mandatory' in terms of education policies across the globe. Schools in Botswana, like anywhere else, use set guidelines to establish PTAs. The guidelines have been drawn to assist both the school heads and parents on how to establish and run PTAs. So, the existence and functioning of a PTA is an expected school-head driven responsibility. However, both the Western (Epstein \& Dauber, 1991; Desforges \& Abouchaar, 2003; Harris \& Goodall, 2006) and African literature (Sifuna, 2007; Pansiri, 2008a; Pansiri \& Pansiri, 2011) are however, awash with evidence that PTAs are weak, and less active. Some barriers of parental participation in both PTAs and education of their children include negative attitude and lack of abilities of parents, poor work and health conditions, and weak leadership knowledge and skills of school heads and teachers (Greenwood \& Hickman, 1991; Hoover-Dempsey \& Sandler, 1997; Pansiri \& Pansiri, 2011) and rurality and remoteness of the communities (Pansiri, 2008b). Greenwood and Hickman (1991) argue that to overcome the barrier, parents want heads of schools to treat them with respect and as equals. Epstein and Dauber (1991) and Greenwood and Hickman (1991 argue that one critical type of involvement of parents in schools, but often failing in most schools, is in decision making, that is, governance and advocacy. So, the functionality of PTA is yet to show results in many schools.

The Western-Euro literature shows that most parents are actively involved and close to teachers and schools at the pre-school or kindergarten and primary or elementary school programs more than middle or secondary school systems (Epstein \& Dauber, 1991). On the contrary, the few studies of primary education programs in Botswana identify marginalization of parents from school instructional management systems in remote schools and the predominance of bureaucratic type of governance where parents are less involved (Pansiri, 2008a; 2008b). Another study discovered little participation by parents in poverty stricken location in urban area (Pansiri \& Pansiri, 2011). Admittedly, little is known in the international literature about issues of PI and PE in Botswana's education system.

The Western-Euro literature or the international literature reveals that parents render significant services to support their children educational programs particularly at pre-school/kindergarten and primary/elementary levels (Epstein \& Dauber, 1991; Hoover-Dempsey \& Sandler, 1997). But generally, children from single parents, whose parents are less schooled, those from poverty stricken families and those in poor, marginalized and remote areas, are at 'high risk' because they receive little support and guidance on their learning from their parents (Thornburg, Hoffman \& Remeika, 1991; Pansiri, 2008b; Pansiri \& Pansiri, 2011). Many studies, however maintain that regardless of the socio-economic and cultural capitals of the children's background, close relationship between home and school or between class and family are important to a child's school success (Bauch, 1993; Hoover-Dempsey \& Sandler, 1995; 1997).

However, different countries face different and sometimes similar challenges in establishing effective PTAs. While PTAs are established institutions to ensure school developments and a child's learning programs, by and 
large, their members play the advocacy role to mobilize parents and other agencies to support school efforts. On the other hand, parents too play an advocacy role on behalf of their children (Olmsted, 1991). In this responsibility, individual parents may participate in the learning program of their children. Literature shows that, unfortunately parents often lack knowledge about their roles and responsibilities at school; feel uncomfortable in school premises; lack opportunities to interact with teachers; encounter cultural barriers between schools and communities; experience ethno-linguistic disconnect between schools and communities (Chavkin, 1993; Pansiri, 2008b; Pansiri, 2011). In some cases, parents "did not want to participate in PTA fundraising activities and prize giving ceremonies [because they] did not want to participate in activities that required money from them" (Pansiri \& Pansiri, 2011, p. 304). Pansiri (2008a) argues that parents saw the school as a property of the teachers where they had little room for assisting, and that remote area dweller (Note 5) parents of primary school boarders were far away from the schools and some did not even know the place where their children were attending school. It seems to be a general issue that parents are at arms length with the schools where their children go. For example, Pansiri and Pansiri (2011, p 303) identify a "social distance between school and home... parents rarely got the opportunity to do some work for the school". They further observed that "there also was social distance between home and the classroom. Teachers did not visit their children's homes, and so opportunities for parents to meet teachers of their children are rare" (p. 304).

Education policies recognize the importance of parents in education. Western literature on this issue is in abundance in the international domain. On the contrary, there is little work known in Botswana on this subject, because not much is available in the international readership. Even if little literature about parenting and education in Botswana is available in the public domain, issues of parents, schools and the community are somehow similar to those experienced in the Western-Euro educational cultures. Critical ones include "family status variables" (Hoover-Dempsey \& Sandler, 1997, p. 7) such as social, economic and cultural capitals of both the children's and parents' backgrounds. Understanding school heads experiences with parenting and education, therefore, remains essential to the Botswana educational planners, policy makers and school practitioners, and in particular the school heads.

\section{Method}

This study adopted the quantitative design and data collection was through the medium of questionnaires. Following Moore (2000) and Simmons's (2003) ideas, questionnaires were used to cover a larger population. This approach was more appropriate for this study because data collection was carried out during a national primary school heads conference held in Gaborone in 2011 where all public primary school heads had attended. However, questionnaires have a disadvantage in that it is uncommon to have all of them returned (Patton, 2002).

At least $63.4 \%(n=473)$ out of a total seven hundred and forty-five $(n=745)$ heads of public or government primary schools responded to the questionnaire. This study adopted a null hypothesis that there was no significance difference between the public primary school heads experiences and challenges they faced with PTAs. Botswana primary school teaching was predominantly female dominated (Pansiri, 2007), hence the 78\% female and $22 \%$ male headteachers who responded to this study. In terms of qualifications, respondents were $49.2 \%$ diploma, $33.2 \%$ bachelors' degree, $16.2 \%$ certificate and $1.3 \%$ masters' degree holders. Their age ranges were 65.5 of $46-55$ year olds, $20.5 \%$ of the $36-45$ year old, $17.4 \%$ of the $56-65$ year olds and $0.6 \%$ of the above 65 years old. In terms of years of experience in school headship positions, $43.3 \%$ were $1-5$ years; $16.8 \%$ were 5 - 10 years; $8.6 \%$ were $11-15$ years; $4.3 \%$ were $16-20$ years; $8.6 \%$ were $21-25$ years; and $18.4 \%$ were above 26 years experienced in school headship position. As for the school location represented, $46.6 \%$ came from small rural villages; $20.8 \%$ from remote area dweller settlements; $20.6 \%$ from major villages; and $12 \%$ from urban/town schools. Both day (96\%) and boarding (4\%) school system were represented. These characteristics represented variables which were being used to predict perceptions and experiences of school heads.

Respondents were selected from an establishment of ten primary education regions through a stratified sampling technique (Gall, Borg \& Gall, 1996). In each of the regions, a representative was asked to issue out the questionnaires to a selected sample. After filling up the questionnaires, respondents returned them through the same route. This ensured $100 \%$ rate of return. The sample accurately represented not only the overall population of school heads, but also key subgroups, such as heads from boarding and day schools, remote, rural and urban locations.

The questionnaire had four sections. The bio-data section was analyzed through the Statistical Packages for the Social Sciences (SPSS) to show frequencies and percentages. The results show the characteristics of schools heads, types and locations schools served. The data were also necessary for purposes of triangulation, to explore 
the relationship between school heads' perceptions and the nature of parental involvement problems they experienced.

The other three sections focused on research objectives and questions. Each question had its own set of items on a five-point likert-scale on factors of parental participation. SPSS was also used in the data analysis to establish and interpret comparisons between and within groups, using bio-data as key variables to generate analysis of variances (ANOVA). The one-way ANOVA on the significance value of $p=.05$ was used to estimate the amount of variance to account for school heads differences in perceptions and/or experiences with PTAs. The last section of the questionnaire was a two-open ended question that required school heads to identify their own challenges on parental participation, and to advance suggestions for a possible solution. To analyze the responses, comments from individual respondents were clustered according to the emerging themes and frequencies were calculated and turned into percentages.

\section{Limitation of the Methodology}

Patton (2002) argues that quantitative research's disadvantage includes poor return of questionnaire. However, $63.4 \%$ return is considered reasonable for this study. The key limitation is that respondents were only school heads, who may, due to their position of responsibility, be guarded in volunteering their opinions and perceptions. For instance it could have been to the advantage of this study if parents had been included. Their exclusion may compromise quality of the information that could influence policy and practice. Lastly, teachers who are not in management positions also play a crucial classroom - parent linkage, and therefore their voice could have provided a balanced view regarding parents' participation in school activities.

\section{Findings and Discussion}

Findings and discussions are guided by the research objectives. The first three objectives on school heads' experiences and perceptions tested the null hypothesis while the last asked respondents to identify challenges faced with their PTAs and parents and suggest strategies to overcome them. The discussion therefore follows this pattern of the questions.

Work of PTA: The assumption that PI or PE benefits child's learning is universal. The concept of PTA was informed by this assumption. The first question tested school heads' perceptions about the work of their PTAs. The majority (48\%) indicated that PTA committee members do not read PTA guidelines, while 39\% indicated that they sometimes do. This data suggest that more PTA members had little knowledge about the work of PTAs. However, the ANOVA shows a .004 degree of significant differences between school heads perceptions according to their locations. There is a relationship between school location and headteachers' experience and perceptions with PTA committee level or ability to read guidelines problems. The data detail shows that those parents who were PTA members in urban areas were more able than those in rural and remote areas.

On whether PTA members received orientation on their expected roles upon election to the committee, $37 \%$ indicated that sometimes they did while $45 \%$ stated that they did not receive any orientation. This data show that, according to the headteachers experiences, little is done to formally introduce PTA committee members on their expected roles. However, an ANOVA of .005 degree of significance reflects that school heads differed in perception according to their 'experience' as school heads. Those more experienced as headteachers felt that orientation was done while the newly promoted felt that no orientation was done for PTA members.

On attendance to committee meetings, while $40 \%$ indicated that PTA members did not come to meetings regularly, $22 \%$ indicated that some members did not come for the meetings altogether, and only $38 \%$ indicated that they often attended PTA meetings. This data suggest that according to the school head experiences, attendance to PTA committee meetings was low. The ANOVA of .011 suggests that age range influenced the way respondents rated PTA committee members' attendance to meetings. The younger school heads rated low attendance while the elderly rated it a little higher. This difference may need further interrogation.

The views of the respondents regarding whether PTA members were enthusiastic about the PTA activities varied with $34 \%$ pointing out that PTA members were not, while another $34 \%$ were of the view that sometimes they were enthusiastic. The other group (32\%) suggested that PTA members were enthusiastic about their work. This data show a level of low participation by committee members. However, age range reflected an ANOVA degree of significance on this question of.011. Compared to elderly ones, younger headteachers felt that PTA committee members were not enthusiastic than the elderly ones. In addition, type (day/boarding) of the school presented an ANOVA of .012. More of the headteachers from boarding schools were of the view that PTA committee members were not enthusiastic about their work. This may be so, given the fact that most of parents of boarders lived far way from the boarding schools. 
When the respondents were asked whether PTAs worked through a plan, $31 \%$ indicated that they did not have plans. Some (32\%) indicated that sometimes they had plans while $36 \%$ indicated that PTAs worked with plans. Regarding the community's knowledge of PTA plans, $63 \%$ indicated that communities do not know the PTA plans, while $17 \%$ stated that the plans were known to their communities. The views of the respondents were also sought on whether plans ensured that parented participate. Their perspectives showed that $62 \%$ felt that PTA plans did not ensure parents' participation in PTA activities. This data suggest that much of the PTA activities were not planned for. However, location showed an ANOVA of .027 of the respondents' perceptions degree of significant difference. In the final anlysis one may safely conclude that, plans are used more in the urban schools than the rural and remote are schools.

Asked whether members were familiar with their roles as per the education policy, $78 \%$ indicated that members did not know their roles and responsibilities. Location reflected an ANOVA of .006 degree of significant differences. This means that headteachers in rural and remote schools felt strongly that PTA members did not know their roles more than the urban ones.

Parental involvement in PTA Activities: The question on the degree of parents' involvement in PTA programs was explored. The majority $(85 \%)$ indicated that parents participated in the election of PTA committee members. On the contrary $70 \%$ pointed out that parents did not participate in the PTA activities despite having elected its executive committee. However length of experience as a headteacher (ANOVA of .004) revealed that the newly promoted ones were more pessimistic about PTA members' participation in activities after being elected than the long service ones. Similarly, those in rural and remote areas also expressed pessimism about PTA members' participation. So in comparison to urban headteachers, those from these areas felt that PTA committee members' participation was low (ANOVA of .036). The respondents (59\%) also indicated that parents did not come to PTA meetings even if they were invited. Only $15 \%$ indicated that parents always attended meetings whenever they were invited. This shows the differences between urban and rural schools in terms of the level of participation in PTA activities. The data showed that headteachers of urban schools experienced better PTA participation than rural and remote schools (ANOVA of .001). Interestingly younger headteachers were more optimistic about PTA members' participation than elderly ones (ANOVA of .005). The same applied to the newly promoted ones, who were more positive than headteachers with more experience in management (ANOVA of .005).

Contribution of ideas to improve school results is an important requirement in the education system. Most (61\%) of the respondents indicated that parents did not contribute ideas to improve school results. The headteachers' perceptions differed according to the locations of schools. The ANOVA reflects a .000 degree of significant difference on their' experiences with the level of parents contribution toward improving school results. Those in rural and remote school experienced very little contribution from parents. On the work of PTAs, $69 \%$ of the respondents indicated that parents did not contribute any ideas to improve the work of PTAs. Rural and remote areas were more affected (ANOVA of .001) compared to urban schools. However, despite where they were, younger headteachers were more optimistic than elderly ones (ANOVA of .002) that parents contributed ideas to improving school results.

Concerning parents' affordability to pay any fees if requested by the school, $82 \%$ of the respondents indicated that parents were unable. Rural and remote headteachers were more affected than urban ones (ANOVA of .000). As to whether they were able to contribute any money if they were requested by the PTAs, $75 \%$ of the respondents indicated that they were unable while only $24 \%$ indicated that they were able. Again rurality and remoteness nature of school location which have an impact (ANOVA of .003) and the type of school (boarding/day) (ANOVA of .006) presented different degree of significance. Asked if parents contributed any money voluntarily to the school, $96 \%$ indicated that parents did not contribute any money to help the school. Regarding parents' voluntary service to schools, $79 \%$ indicated that parents did not volunteer their services to help their schools.

To sum up this sub section, the results show that schools apply the democratic methods to elect PTAs. The capacity of parents to serve and participate in committee programs is lacking. According to the school heads experiences, the involvement of parents in PTA activities is lacking because they fail to respond to PTA invitation, do not contribute ideas that help to improve school results, and do not volunteer their services to help the school. The urban - rural - remote differences appear to be a factor. This factor accounts for the absence of home - school functional partnership and collaboration or a problematic social distance (Pansiri \& Pansiri, 2011) between home and school. PTAs do exist in name but not in function. However and despite the location factor, younger and newly promoted headteachers appear more optimistic about the level of involvement and contribution by both PTA committee members and parents more than the elderly and more experienced. This is one factor that may need to be further investigated. 
Parental Support to children's learning: The study explored parental support for their children at school. While some children could still succeed in their schooling without any direct involvement of parents, literature maintains that PI and PE play a major role in helping learners to achieve from the best of their potential (Hoover-Dempsey \& Sandler, 1995). These scholars argue that parents become involved in their children's education through invitations or demands or opportunities presented by either the child or the school (1997, p. 9). Parents' support comes in various forms. The school heads in this study also presented varied experiences of parents support. Asked whether parents visited schools to discuss their children learning progress, $82 \%$ of the respondents indicated that parents did not visit schools.

On whether parents volunteer teaching services to their schools, $93 \%$ of the respondents indicated that parents did not volunteer to help teachers in the classroom with teaching. However, the degree of variance appeared between rural/remote and urban schools (ANOVA of .003). Asked if parents assisted children with homework, $87 \%$ indicated that parents did not assist children with home work. Again, a clear variance according to location (rural/remote versus urban) reflected an ANOVA of .000. The variance also appeared according to the type of schools (day versus boarding) with an ANOVA of .029 degree of significant difference of the respondents' perceptions and experiences with parents' effort to assist children with homework. On whether parents encouraged children to engage in learning at home, $84 \%$ indicated that parents did not. Location (rural/remote versus urban) had an ANOVA of .000. On the contribution of parents to encourage children to do library reading, 91\% indicated that parents did not encourage children to participate in library reading. Location (rural/remote versus urban) had an ANOVA of .000 degree of significance on the respondents' experiences on the role of parents in encouraging children to participate in library reading. In response to whether parents ever make donations of teaching materials to the schools, $91 \%$ of the respondents indicated that parents did not give donations of any teaching materials to their schools. On assistance parents give to teachers to fight children's anti-social behavior, 38\% indicated that parents did not assist schools, $35 \%$ indicated sometimes they did and $24 \%$ agreed that parents were available to assist teachers. Furthermore, a majority (38\%) indicated that parents were unable to purchase sufficient school clothing, while 32\% indicated that they sometimes did and $27 \%$ suggested that parents were able. Location (rural/remote versus urban) reflected an ANOVA of .000. Age range too showed an ANOVA of .002 degree of significance on the respondents' perceptions. However $86 \%$ of respondents were of the view that parents failed to pay development fees required by the school.

Hoover-Dempsey and Sandler's (1997) model of three level construct of PI is useful to explain these findings. The model suggests that the decision and choice to participate depends of the parent's ideas and experiences. Parents participate if they know their role in child's life, or if they have a sense of efficacy or if they are invited to do so. It seems, according to the school heads experiences, that parents' engagement in children learning programs both at home and in public schools is lower in remote and rural than in urban. That is why 'location' (46.6\% from small rural villages; $20.8 \%$ from remote area dweller settlements; $20.6 \%$ from major villages; and $12 \%$ from urban schools) features so prominently as an issue in the school heads experiences. Pansiri (2008a) and Pansiri and Pansiri (2011) found a correlation between parents' level of education and PE. The better educated parents and those in better socio-economic status tend to establish a stronger home-school alliance and become more engaged with their children's learning than the less educated and the poor. The absence of home-school alliance in the Botswana boarding primary schools which serve the RADs communities is obvious (Pansiri, 2008b). Government supplies everything (clothing, toiletry, bedding, food) to the child; hence the prevalence of the bureaucratic type of governance where parents are not part of the learning support mechanism is what most school heads in this study experience (Pansiri \& Pansiri, 2011).

Challenges facing PTA: School heads were asked to mention critical challenges they experienced with the parental involvement. They came up with three challenges. The majority (54\%) identified low turn up to PTA meetings as a major challenge. The other $53 \%$ pointed to lack of parental support and participation in school activities. A few (11\%) identified ineffective PTA committee as a critical issue in schools.

Asked to propose solution to the challenges, $45 \%$ of the respondents advanced parents' education in the form of induction and orientation on their role in education of their children. A significant number (34\%) suggested that PTA committee members be given an allowance for the services they were rendering. A few (7\%) proposed the provision of 'simple and clear' PTA guidelines.

\section{Conclusion and Recommendation}

There seem to be consistency in the headteachers' perceptions regarding the level of PI in schools in Botswana. PTA members of public primary schools in Botswana do not receive orientation and as such many do not read PTA guidelines. Many PTA committee members and particularly those who are in rural and remote areas do not 
know their roles and responsibilities. They do not come to meetings regularly and they do not have plans to guide their activities. If they do, PTA plans do not result in parents' active participation in PTA activities. On a positive note, PTAs do consult parents regularly. However, Pansiri and Pansiri (2011) discovered that parents in urban centres fail to participate in PTA activities, because the activities are held during the day and during the week when they were at work. In remote schools, Pansiri (2008b) discovered that parents of RADs children in boarding primary schools who stay far away from the schools did not participate in PTA activities. He attributed this problem to the reasons of poverty, low literacy levels, lack of money to visit schools, no transport, and clash of home/school cultures particular in the case of the RADS. However, and as revealed in this study and by litierature about both urban and rural/remote cases, PTA programs in Botswana public primary schools, were ineffective, hence, the bureaucratic type of school governance (Pansiri, 2008a) where parents play a little role in the PTA activities. This analysis also confirms Sifuna's (2007) argument that parent - school disconnection in the African government supplied education systems was a common trend. This, he argues, was due to little schooling demand from the community.

The critical challenge in as far as Botswana headteachers of public primary schools' experience is concerned is minimal parental support. Parents participate less in school activities, and they turn up for PTA committee meetings very slowly. The situation is more challenging for parents in rural areas and those with children in boarding primary schools, who live far away from where the schools are located, resulting in an absence of both the internal and external interaction between the family, home and community (Epstein, 1995). While school heads observed that parents needed an education program that would train them to understand and appreciate varied family, school and community impacts in education, differences in perceptions were influenced more by contexts of locations of schools. School heads in the difficult locations need to have some incentives that could be used to attract and motivate parents to associate with school demands for their attention. However, the voice of the parents is yet to be heard over these issues. Three recommendations are nevertheless drawn from these conclusions. These are:

1) The Botswana education systen should develop a parent education programme which is context friendly to all locations in Botswana in order to encourage parents to understand and appreciate family, school and community impact on education and assist them to participate in school developments and children's learning programs at all levels.

2) The education sector should promulgate a policy that could support parents of children, especially those whose children are in remote areas and in boarding schools, so that they can eaisly access and participate in school activities where their children attend.

3) Further research to determine variances in ages and lengths of service of school heads, and to hear the voices and experiences of parents should be carried out by both researchers and policy makers.

\section{References}

Bauch, A. P. (1993). Improving education for minority adolescents: towards an ecological perspective on school choice and parental involvement. In N. F. Chavkin (Ed.), Families and schools in a pluralistic society (p. 121-156). New York: State University of New York Press.

Berger, H. E. (1991). Parent involvement: yesterday and today. The Elementary School Journal, 91(3), 209-219.

Chavkin, N. K. (1993). Families and the schools. In N. F. Chavkin (Ed.), Families and schools in a pluralistic society (pp. 2-17). New York: State University of New York Press.

Desforges, C., \& Abouchaar, A. (2003). The Impact of Parental Involvement, Parental Support and Family Education on Pupil Achievement and Adjustment: A Literature Review. Nottingham: DfES.

Epstein, J. L. (1995). School/family/community partnership: caring for the children we share. Phi Delta Kappa, 701-711.

Epstein, J. L., \& Dauber, S. L. (1991). Research and practice in parent involvement: implications for teacher education Elementary and Middle School. The Elementary School Journal, 1(3), 289-303.

Greenwood, E. G., \& Hickman, W. C. (1991). Research and practice in parent involvement: implications for teacher education. The Elementary School Journal, 91(3), 280-288.

Harris, A., \& Goodall, J. (2007). Engaging Parents in Raising Achievement: Do Parents Know They Matter? Warwick: Department for Children, Schools and Families.

Hoover-Dempsey, V. K., \& Sandler, M. H. (1995). Parental involvement children's education: why does it make a difference? Review of Educational Research, 97(2), 310-331. 
Hoover-Dempsey, V. K., \& Sandler, M. H. (1997). Why do parents become involved in their children's education? Review of Educational Research, 67(1), 3-42. http://dx.doi.org/10.3102/00346543067001003

Le Roux, W. (1999). Torn Apart: A report on the educational situation of San children in Southern Africa. Commissioned by Kuru Development Trust and WIMSA.

Moore, N. (2000). How to Do Research: The Complete Guide to Designing and Managing Research Projects (3rd ed.). London: Library Association Publishing.

Nyati-Ramahobo, L. (2004). Language planning and policy in Africa. In R. B. Baldauf, Jr., \& R. B. Kaplan (Eds.), Language planning and policy in Africa, 1. (Vol. 3, pp. 21-78). Ontario, Canada: Multilingual Matters Ltd.

Olmsted, P. P. (1991). Parent involvement in elementary education: findings and suggestions from the follow through program. Elementary School Journal, 91(3), 221-231.

Pansiri, L., \& Pansiri, O. N. (2011). Causes of poor parental involvement: case study of a primary school in Gaborone West - Botswana. Pula Journal of Educational Studies, 25(4), 471-494.

Pansiri, O. N. (2007). Teacher Remuneration: A Critical Policy Review in Botswana. Pula - Journal of African Studies, 21(1), 199-217.

Pansiri, O. N. (2008a). Instructional Leadership for Quality Learning: An Assessment of the Impact of the Primary School Management Development Project in Botswana. Educational Management, Administration and Leadership, 36(4), 471-494. http://dx.doi.org/10.1177/1741143208095789

Pansiri, O. N. (2008b). Improving Commitment to Basic Education for the Minorities in Botswana: A challenge for Policy and Practice. International Journal of Educational Development, 28(4), 446-459.

Pansiri, O. N. (2011). Performativity in school management and leadership in Botswana. Educational Management Administration and Leadership, 39(6), 751-766. http://dx.doi.org/10.1177/1741143211416386

Pridmore, P. (1995). Learning and Schooling of Basarwa (Bushmen) children in Botswana. Prospects, XXV(4), 707-722.

Republic of Botswana. (1993). The Report of the National Commission on Education of 1993. Ministry of Education. Gaborone: Government Printer.

Republic of Botswana. (2011). 2011 Population and Housing Census: Preliminary Results Brief. Ministry of Finance and Development Planning. Gaborone: Central Statistics Office.

Republic of Botswana. (1977). Education for Kagisano: Report of the National Commission on Education. Gaborone: Government Printers.

Republic of Botswana. (1994). The Revised National Policy on Education. Gaborone: Government Printers.

Sifuna, D. N. (2007). The Challenge of Increasing Access and Improving Quality: An Analysis of Universal Primary Education Interventions in Kenya and Tanzania since the 1970s. International Review of Education, 53(5-6), 687-699. http://dx.doi.org/10.1007/s11159-007-9062-z

Simmons, R. (2003). Questionnaires. In N. Gilbert. (Ed.), Researching Social Life (2nd ed., pp. 85-104). London: Sage Publications.

Thornburg, R. K., Hoffman, S., \& Remeika, C. (1991). Youth at risk; society at risk. The Elementary School Journal, 91(3), 199-208.

\section{Notes}

Note 1. Bechuanaland is the name of Botswana during colonial rule.

Note 2. Local authorities are district councils established by the 1965 Act of Parliament.

Note 3. Western-Euro countries are developed countries of United States of America and Europe.

Note 4. RADP is a programme mandates to provide basic social services in order to achieve sustainable social and economic development of all people in the remote areas classified as Remote Area Dwellers.

Note 5. Remote area dwellers are low-income ethnic minority families, with limited Setswana proficiency, poorly educated, living in geographically hard to reach settlements and are taken care under RADP. 